\title{
POSITIVE EMOTIONS IN EDUCATION
}

\author{
REINHARD PEKRUN, THOMAS GOETZ, WOLFRAM TITZ, \\ AND RAYMOND P. PERRY
}

Positive emotions are essential for human behaviour and adaption. They help to envision goals and challenges, open the mind to thoughts and problem-solving, protect health by fostering resiliency, create attachments to significant others, lay the groundwork for individual self-regulation, and guide the behaviour of groups, social systems, and nations. In spite of their many functions, however, positive emotions have been neglected by psychology. Until recently, psychology has focused on the dark side of human life. Psychopathological behaviour, negative emotions emanating from stress, and coping with stress and negative emotions have been studied extensively, whereas adaptive behaviour, positive emotions, and proactive coping did not receive that much attention (cf. Frydenberg 1997; Fredrickson 2001). Furthermore, traditional theories addressing the functions of positive emotions for cognition and behaviour have focused on negative effects of positive emotions, instead of their regulatory benefits (cf. Aspinwall 1998).

Educational settings are of specific importance for shaping human self-regulation and development, and students' and teachers' positive emotions can be assumed to be central to attaining these educational goals. However, educational psychology and educational research in general were no exception in neglecting positive emotions. Specifically, whereas students' test anxiety has been studied extensively, positive emotions related to learning and achievement have rarely been analysed. This seems to be true, in spite of the fact that anticipatory hope and pride relating to success and failure were deemed key determinants of achievement motivation and task behaviour by traditional theories of achievement motivation, along with anticipatory fear and shame (cf. Atkinson 1964; Heckhausen 1980). Studies on achievement motivation included items pertaining to these emotions in global measures of achievement motives, but rarely studied emotions in their own right. Specifically, this pertains to the positive emotions of hope and pride which were only regarded as components of the motive to achieve success. The motive to avoid failure, on the other hand, has often been equated with test anxiety on an operational level, having been assessed by test anxiety questionnaires in many studies (Atkinson 1964). Concerning positive emotions relating to learning, instruction, and achievement, the only major tradition of research addressing such emotions directly was attributional theory originating from Bernard Weiner's programme of research on achievement emotions (cf. Weiner 1985). This research produced a sizable number of studies analysing links between causal attributions of success and failure, and a variety of positive achievement-related emotions. 
Table 8.1 Literature Search 1974-2000: studies linking emotions to learning and achievement

\begin{tabular}{lccl}
\hline & {$[1974-1990]$} & {$[1991-2000]$} & Research tradition \\
\hline Joy & 32 & 29 & Mood research \\
Enthusiasm & 9 & 7 & Teacher enthusiasm \\
Hope & 0 & 9 & \\
Relief & 2 & 1 & \\
Pride & 17 & 10 & Achievement motivation \\
Gratitude & 2 & 1 & \\
Admiration & 0 & 0 & Mood research \\
Sadness & 10 & 5 & Type A personality \\
Anger & 31 & 33 & Test anxiety \\
Anxiety & $>700$ & $>500$ & Hopelessness theory \\
Hopelessness & 2 & 12 & Achievement motivation \\
Shame/guilt & 24 & 20 & \\
Disappointment & 2 & 0 & Job monotony \\
Boredom & 27 & 16 & \\
Envy & 5 & 1 & \\
Contempt & 0 & 0 & Attributional theory \\
Surprise & 6 & 1 & \\
\hline
\end{tabular}

Beyond attributional research, we lack studies on positive emotions in education, and in learning and achievement generally. This is evident from a review of the literature by Pekrun and Frese (1992) updated recently (Pekrun et al. in press; cf. Table 8.1). Concerning positive emotions, this search pertained to all studies linking any of the emotions listed in Table 8.1 to the topics of learning, work, performance, test, and achievement, thus extending well beyond the educational domain and including achievement-related emotions at work and in sport as well. Apparently, whereas more than 1000 studies addressed achievement-related anxiety to date, and more than 200 studies other negative achievement emotions (like anger, shame, or boredom), the total number of studies addressing positive achievement-related emotions was less than 10 per cent of those addressing negative emotions.

In our own research on students' academic emotions, we therefore made an attempt to pay no less attention to positive emotional experiences in education than to negative emotions. Positive emotions are important for both students and teachers. In this chapter, however, we focus on the student side of educational settings. More specifically, we give an overview of our research addressing students' academic emotions, that is, their emotions relating to learning, instruction, and achievement in academic settings associated with attending class, studying, and taking tests and exams (Pekrun et al. in press). In so doing, we address the following problems in turn: (1) How frequently are positive emotions experienced by students at school and university, and which positive emotions play a role in academic settings (occurrence)? (2) How can students' positive emotions be assessed (measurement)? (3) How do these emotions influence students' learning and achievement (effects)? (4) What are the origins of these emotions in students' personality, classroom instruction, and social environments, and what can be done to foster them (antecedents and intervention)? In conclusion, we will stress the importance of strengthening research on 
positive emotions as well as positive emotion-based intervention in general, and in education specifically.

\section{The occurrence of positive academic emotions: exploratory studies}

Learning and achievement are among the most important topics across the life span today. This implies that they should be major sources of emotion, since by definition, emotions are reactions to important events and states. Academic settings of learning and achievement can thus be assumed to produce a variety of intense emotions, including both negative and positive emotions, and task-related as well as self-related and social emotions (see Table 8.2 for examples). However, the extent to which students' affective life is characterized by positive emotions has not yet been determined. There is converging evidence that motivational experiences relating to positive emotions tend to decline throughout the school years. This seems to be true for students in North America, as well as for Australian and European students. Examples are decreasing average values for students' self-concepts of academic abilities, interest in academic subject matters, and intrinsic motivation (cf. Pekrun and Fend 1991; Gottfried et al. 2001). To which extent do students, nevertheless, experience positive emotions?

To date the evidence to answer this question seems to be lacking. In a series of five qualitative studies, we explored university and secondary school students' emotions experienced in academic settings. In the first of these studies, university students were requested to recollect academic situations and emotions experienced in these situations from their autobiographical memories. The other four studies used a less retrospective format by asking students for their emotional experiences immediately after they had attended a class, finished a period of studying, or taken a test or exam. In all of these studies, oral or written narratives were gained by asking students a series of fixed questions, without providing any more formal prescriptions on how to answer them. Three of the studies did so by using interviews which were recorded and transcribed, the other two by questionnaires (cf. Pekrun 1992a; Spangler et al. in press; Titz 2001).

Table 8.2 The Domain of academic emotions: examples

\begin{tabular}{|c|c|c|}
\hline & Positive & Negative \\
\hline \multicolumn{3}{|c|}{ Task- and self-related } \\
\hline Process & Enjoyment & Boredom \\
\hline Prospective & $\begin{array}{l}\text { Anticipatory joy } \\
\text { Hope }\end{array}$ & $\begin{array}{l}\text { Hopelessness } \\
\text { Anxiety }\end{array}$ \\
\hline Retrospective & $\begin{array}{l}\text { Joy about Success } \\
\text { Satisfaction } \\
\text { Pride } \\
\text { Relief }\end{array}$ & $\begin{array}{l}\text { Sadness } \\
\text { Disappointment } \\
\text { Shame/guilt }\end{array}$ \\
\hline Social & $\begin{array}{l}\text { Gratitude } \\
\text { Empathy } \\
\text { Admiration } \\
\text { Sympathy/love }\end{array}$ & $\begin{array}{l}\text { Anger } \\
\text { Jealousy/envy } \\
\text { Contempt } \\
\text { Antipathy/hate }\end{array}$ \\
\hline
\end{tabular}


Data were analysed by using qualitative and quantitative methods. For purposes of quantitative analysis, a system for classifying emotional experiences was developed and used to integrate the narratives which our subjects had delivered. This descriptive classification system was based both on the accounts which our subjects had given, and on theoretical considerations derived from the literature. Originally, it contained a rather exhaustive set of 44 different categories of emotional experiences. However, it turned out that many of these categories pertained to different intensities and qualities of one and the same underlying emotion (e.g. fear and panic, both pertaining to the primary emotion of anxiety), such that 14 summary categories of academic emotions could be used to integrate most of the results.

The findings of the first study were typical for the other investigations as well. In this study, we had asked for experiences in three major types of academic situations: attending class, studying, and taking tests or exams. Interviews were conducted in such a way that the number of reports was balanced across situations. Overall, anxiety was the one emotion which was reported most often by the 50 university students interviewed, accounting for 19 per cent of all 414 emotional episodes reported. This finding corroborates assumptions about the prevalence of students' anxiety (Zeidner 1998).

However, in spite of the importance of anxiety and other negative emotions, it turned out that positive emotions were reported no less frequently than negative emotions. Concerning major categories of emotion, 37.5 per cent of all reports pertained to negative emotions, but no less than 40.5 per cent to positive emotions. The other 22 per cent of the reports related to affectively more neutral emotions like surprise, and to emotions which were reported less frequently or proved not to be classifiable by our system. Positive emotions reported most often were enjoyment ( 13.7 per cent), relief ( 8.6 per cent), satisfaction/contentment ( 6.0 per cent), hope ( 5.0 per cent), curiosity/interest ( 4.1 per cent), and pride (3.1 per cent). In addition to these major categories of positive emotions, a number of less frequently reported positive emotions played a role as well. Specifically, this applied to social positive emotions like sympathy and admiration.

The frequency of positive emotions depended on the type of situation addressed, however. For situations related to studying, attending class, and taking tests or exams, frequencies of positive emotions reported were 57.2, 52.3, and 31.2 per cent, respectively. Structural and functional differences between these situations can probably be made responsible for different profiles of frequencies. Specifically, university students' positive emotions may depend on the relative autonomy given to students, and on opportunities for success. Normally, there are more opportunities for autonomy and self-regulation in situations of studying, compared to attending class or taking tests, and, for many students, better chances for experiencing success while studying and attending class, compared to taking tests and exams.

Beyond giving accounts of emotions per se, the narratives our subjects delivered also described the experienced sources and effects of academic emotions. Specifically, the questions we asked covered cognitive and motivational processes experienced in the respective situations, as well as subjective experiences of physiological processes, and of social interactions. Contingency analysis showed that emotions were systematically connected to cognition, motivation, physiological changes, and interaction patterns. 
For example, the contingency coefficient for relations between emotions and frequencies of specific cognitive appraisals within academic situations was $0.60\left(\chi^{2}(196)=476.69\right.$, $p<0.001$; Pekrun 1992a). Concerning the three often reported positive emotions of enjoyment, satisfaction/contentment, and relief the following patterns of cognitive appraisals appeared to be typical. Enjoyment was systematically related to two different types of cognitions: thoughts about the learning material, on the one hand, and appraisals of mastery and success, on the other. Apparently, academic enjoyment can take process-related forms pertaining to learning activities, or outcome-related forms pertaining to resulting achievement and its consequences. Satisfaction and contentment, on the other hand, turned out to be outcome-oriented emotions. One primary source were appraisals of mastery and success. Another relevant type of appraisal was the perceived usefulness of academic learning (e.g. for instrumental purposes pertaining to one's anticipated future job). Relief, finally, was characterized by a pattern of appraisal correlates parts of which might seem counterintuitive at first sight. Generally, relief is an emotion which is triggered by the cessation of aversive circumstances. In our data, relief was related to appraisals of success and mastery in some cases, but to appraisals of non-mastery and failure in others. In any case, however, it pertained to the end of an aversive phase of studying, the end of taking a stressful test or exam, or a reduction of stress experienced during the course of a test or exam.

In sum, our exploratory studies corroborated the assumption that positive emotions may be no less characteristic of students' affective life than their negative emotions. Concerning situations of attending class and studying, they were reported slightly more often than negative emotions. Even concerning exams, however, positive emotions accounted for more than one-third of the emotions reported. This was true not only for samples of university students, but for secondary school students' academic experiences as well (cf. Holzwarth 1997; Rapp 1997; Titz 2001). The ubiquitous frequency of positive academic emotions implies that it should prove fruitful to examine them empirically, and to address them when designing instruction and educational interventions.

\section{Measurement of positive academic emotions: the Academic Emotions Questionnaire (AEQ)}

Whereas exploratory, qualitative methods are well suited to gaining preliminary insights into phenomena which have not yet been investigated thoroughly, quantitative measurement is needed for the more precise analysis of effects and causes. Instruments measuring positive academic emotions are lacking to date. Previous research addressing such emotions has either used more global measures of human emotions not pertaining to the academic domain, or single rating scales using one item per emotion (see Puca and Schmalt 1999; Turner and Schallert 2001). However, global measures of emotion may be less predictive of academic learning and achievement than more specific instruments, as may be seen, for example, from the fact that students' general trait anxiety correlates less with achievement than their test anxiety (Hembree 1988). Single-item scales, on the other hand, may lack reliability, and cannot capture the internal structures of academic emotions in adequate ways. 
We therefore developed a quantitative self-report instrument measuring a number of more important academic emotions by multi-item scales (Academic Emotions Questionnaire, AEQ; for an overview, see Pekrun et al. in press). This instrument comprises 24 scales measuring nine emotions (enjoyment, hope, pride, relief, anger, anxiety, shame, hopelessness, and boredom) in three different academic settings (attending class, studying, and taking tests and exams).

\section{Theoretical considerations and scale construction}

The selection of emotions to be included was based on criteria relating to frequency and theoretical relevance. Specifically, we wanted to measure emotions which were reported frequently in our exploratory research, and can be assumed to be important for students' learning and achievement. The resulting set of emotions comprises four positive emotions, namely, enjoyment, hope, pride, and relief. In addition, the AEQ measures five negative emotions (anger, anxiety, shame, hopelessness, and boredom). Concerning positive emotions, our choice of emotions implied that four of the six most often reported emotions were included (see last section). Pride was included instead of the more often reported emotion of contentment since pride can be assumed to be of primary relevance for students' motivation (Heckhausen 1980).

However, whereas there is no dispute that enjoyment, pride, and relief are human emotions, the construct of hope is considered to be more problematic. Specifically, hope is viewed as a cognitive construct instead of an emotion by some authors. For example, Snyder's theory conceptualizes hope as a set of cognitive expectations relating to pathways and agency in the pursuit of goals (cf. Curry et al. 1997). There are two main reasons why we conceptualized hope as an emotion.

First, concerning anticipatory emotions relating to future events, hope can be considered the one positive emotion which is complementary to the negative emotion of anxiety. Both hope and anxiety imply subjective uncertainty about future events, in contrast to anticipatory joy and hopelessness implying subjective certainty. Whereas anxiety involves an amalgam of negative feelings and appraisals of uncertainty, hope involves a combination of feeling positive about a future event, wanting the event to happen, and appraising this as being uncertain. Second, consistent with such a view, subjects in our exploratory research had reported about hope as an emotional experience implying 'hot' expectations instead of cold cognition, implying that the experience of hope was not restricted to affectively neutral cognitive appraisals.

We decided to construct separate scales measuring the emotions listed above for situations of attending class, studying, and taking tests and exams. These situations differ with respect to their functions and social structures, implying that related emotions can differ as well. For example, enjoying studying at home may be quite different from enjoying the challenge of an exam. However, we also decided not to measure all emotions with respect to all three types of situations. Specifically, relief is measured for test situations only, and boredom for situations of attending class and studying. The other seven emotions are measured for all three types of situations. Accordingly, there are eight scales per situation, and a total of 24 scales in the instrument.

Concerning the internal structures of academic emotions, we adopted component process views conceptualizing emotions as sets of interrelated psychological processes (e.g. Scherer 
Table 8.3 Academic Emotions Questionnaire (AEQ): reliability of the trait scales

\begin{tabular}{|c|c|c|c|c|c|c|}
\hline \multirow[b]{3}{*}{ Emotions } & \multicolumn{6}{|c|}{ Scales } \\
\hline & \multicolumn{2}{|c|}{ Learning-related emotions } & \multicolumn{2}{|c|}{ Class-related emotions } & \multicolumn{2}{|c|}{ Test emotions } \\
\hline & $\alpha$ & Items & $\alpha$ & Items & $\alpha$ & Items \\
\hline Enjoyment & 0.90 & 14 & 0.89 & 15 & 0.90 & 23 \\
\hline Hope & 0.86 & 9 & 0.84 & 9 & 0.89 & 16 \\
\hline Pride & 0.84 & 9 & 0.86 & 9 & 0.92 & 16 \\
\hline Relief & $-^{\mathrm{a}}$ & - & - & - & 0.89 & 14 \\
\hline Anger & 0.89 & 14 & 0.85 & 11 & 0.89 & 17 \\
\hline Anxiety & 0.92 & 18 & 0.89 & 13 & 0.94 & 31 \\
\hline Hopelessness & 0.93 & 13 & 0.88 & 10 & 0.94 & 21 \\
\hline Shame & 0.90 & 14 & 0.91 & 15 & 0.93 & 19 \\
\hline Boredom & 0.93 & 17 & 0.93 & 14 & $-b$ & - \\
\hline
\end{tabular}

${ }^{a}$ Relief scale for test emotions only.

boredom scale for learning-related and class-related emotions only.

1984), including affective, cognitive, physiological, as well as motivational processes. For example, important component processes of task-related enjoyment can be to feel excited when tackling the task, appraise the task as challenging, experience physiological arousal, and be motivated to work at the task. Such a view is in line with contemporary conceptions of students' test anxiety (cf. Hodapp and Benson 1997), although we regard motivational components as no less important than affective-physiological and cognitive components traditionally considered by test anxiety research.

Based on these considerations, we developed an initial item pool, extracted items for preliminary versions of the scales, tested these preliminary versions, and selected items for the final scale versions (see Table 8.3 for an overview). The items are worded such that the scales can be used with alternative instructions pertaining to trait academic emotions, course-related academic emotions pertaining to a specific course or class, and state academic emotions experienced within single academic episodes. Also, there are short eight-item versions of the scales. Recently, the short versions of the scales have been translated into the English language (Götz et al. 2001).

\section{Reliability and structural validity}

Table 8.3 provides an overview of the reliabilities of the trait versions of the scales, which turned out to be quite satisfactory ( $N=230$ university students for the learning-related and class-related scales, and $N=222$ for the test-related scales; Molfenter 1999; Titz 2001). The reliabilities for the short trait versions, English-language short trait versions, courserelated versions, and state versions proved to be sufficiently high as well (average Alphas were $0.86,0.86,0.87$, and 0.86 , respectively; cf. Titz 2001; Pekrun et al. in press; Goetz et al. 2001).

Confirmatory factor analysis was used to analyse the internal structures of the scales. Results implied that the scales show sufficient homogeneity, but nevertheless consist of differentiated internal structures pertaining to different components of emotions 
(i.e. affective, cognitive, physiological, and motivational components). For most of the scales, hierarchical latent factor models comprising separate first order factors for different emotion components, and one second-order factor representing the whole emotion, proved to have a better fit to the data than simple one-factor models. For learning-related enjoyment, a more complicated structure emerged, since this scale pertains both to enjoyment of learning activities, and to enjoyment of mastery and success resulting from learning (for a summary of confirmatory factor analyses, cf. Titz 2001).

The interrelations between learning-related, class-related, and test-related emotions proved to be moderate (average $r=0.61$ ), thus corroborating that academic emotions pertaining to these three types of academic situations can be differentiated. Within each of these three groups, several clusters of emotions emerged. The positive emotions of enjoyment, hope, and pride constituted one such cluster for each of the three types of academic situations. This cluster did not represent all relevant positive emotions, however. Specifically, relief separated out by constituting a cluster on its own (Molfenter 1999). Enjoyment, hope, and pride showed close intercorrelations, though well below the respective reliabilities (average $r=68$; Molfenter 1999; Titz 2001). Correlations between these three emotions and relief, on the other hand, were weaker $(r=0.28,0.03$, and 0.26 between test-related enjoyment, hope, and pride, on the one hand, and test-related relief on the other; Molfenter 1999).

From a theoretical perspective, this pattern of interrelations makes perfect sense. It is conceivable to regard enjoyment, hope, and pride as specific variants of one primary positive emotion, namely, joy. Hope can be considered a future-oriented variant of joy implying subjective uncertainty of upcoming positive events, and pride a more retrospective variant of joy implying internal attributions of past or present positive events which are interpreted as a person's own accomplishments. Furthermore, enjoyment, hope, and pride share activating properties. In contrast, relief is a tension-reducing, deactivating emotion which is tied to the cessation or avoidance of a negative state. In the academic realm, one important case in point relates to negative states of test-related stress and anxiety, thus explaining why the positive emotion of test relief correlated positively with the negative emotion of test anxiety ( $r=0.39$; Molfenter 1999).

In sum, this evidence shows that the AEQ is a multidimensional self-report instrument which measures students' emotions in reliable and factorially valid ways. Moving beyond reliability and structural validity, we also assessed the functional construct validity of the AEQ scales concerning relations to students' learning, achievement, personality, and social environments. These relations will be addressed in the next two sections. It should also be noted, however, that the domain of positive academic emotions is not exhaustively covered by the AEQ, and probably cannot completely be measured by any single instrument. Whereas the four positive emotions included may be of specific importance, there are further positive emotions which can play a role in academic situations as well (e.g. contentment, sympathy, and admiration).

\section{The impact of positive emotions on students' learning, self-regulation, and achievement}

Many traditional conceptions of human emotions attributed negative functional properties to positive emotions, postulating that positive emotions induce unrealistic appraisals, 
lead to shallow, superficial processing of information, and reduce motivation to become more deeply involved with the pursuit of challenging goals (cf. the cogent overview given by Aspinwall 1998). Do such accounts represent reality? Are positive emotions detrimental to students' academic learning, self-regulation, and achievement?

In order to obtain preliminary answers to these as yet largely unanswered questions, we first provide short accounts of previous theories and research on the impact of positive mood and positive emotions. We then present a summary of assumptions deduced from a cognitive-motivational model of the achievement effects of emotions (Pekrun 1992b), and discuss findings derived from a series of cross-sectional and longitudinal field studies on students' positive emotions which tested parts of these assumptions.

\section{Research on effects of positive mood}

Theories and research on the impact of positive affect have focused on positive mood, whereas discrete positive emotions have received much less attention. Over the past twenty years, a multitude of theories have been formulated which address effects of positive and negative mood on cognition and behaviour. These theories relate mood to specific cognitive processes like social perception, attitudes, memory, judgement, problem-solving, decision-making, and health-related appraisals (cf. Aspinwall 1998), and use assumptions on specific mediating processes to give accounts of mood effects within these areas. As a result, there are many theories today, some of them addressing rather specific combinations of mood effects and mediating processes. Although most of these theories seem to be substantiated by some body of research, they are often conflicting, and a more comprehensive theoretical framework reconciling them seems not to be in sight. Four more general approaches, however, can be differentiated, each of which seems to attribute negative functional properties to positive emotions. In summarizing this work, we necessarily have to give a simplified account of each of these approaches (for more detailed reviews, see e.g. Aspinwall 1998; Forgas 1995; Isen 1999; Schwarz and Clore 1996).

Mood-congruent effects. Following the pioneering work by Bower (1981) on mood and activation in semantic memory networks, mood has been postulated to serve as a cue for encoding and retrieving mood-congruent material from memory, thus enhancing storage and retrieval of positive material in positive mood states, and of negative material in negative mood states. Mood-congruent retrieval effects have consistently been found in experimental research. Recently, mood congruent retrieval effects have also been shown for emotion-specific mood states (Levine and Burgess 1997). Mood congruency has been postulated to interfere with effective self-regulation. Specifically, it has been assumed and corroborated empirically that positive mood can lead to an overestimation of chances to obtain positive outcomes due to mood-congruent retrieval of positive outcome-related probability judgments, and to an underestimation of the likelihood of negative events such as failure and illness (cf. Schwarz and Bohner 1996). Unrealistic appraisals of present circumstances and future events, however, can be detrimental to efficient self-regulation and goal pursuit, implying that positive mood can be dysfunctional.

Mood as information serving motivation. In safety-signal and mood-as-information approaches, the informational properties of mood and the motivational effects of these properties have been addressed (cf. Clore et al. 1994). Specifically, these approaches have assumed that negative mood signals unsafe conditions, thus inducing motivation to engage in elaborate cognitive problem-solving and effortful action. Positive mood, on the other 
hand, signals safe conditions, thus allowing for relaxation and counteracting any more systematic and careful processing of information. Again, this would imply that positive mood should be detrimental to efficient self-regulation, since relaxation and superficial information processing may compromise any long-term, effortful goal pursuit.

Mood as a goal of motivation. In this group of approaches, it is assumed that humans are motivated to maintain positive mood (mood maintenance), and to reduce or avoid negative moods (mood repair; cf. Schaller and Cialdini 1990). Motivation to maintain positive mood, however, is supposed to induce avoidance of negative thinking and of taking risks. Avoidance of thinking about negative aspects of the self, present, and future, however, can also be quite maladaptive from the perspective of cautionary, proactive longterm goal pursuit.

Mood effects on cognitive resources. Finally, from a variety of theoretical perspectives, it has been postulated that mood can distract attention, which would lead to superficial information processing. Specifically, the resource allocation model put forward by Ellis and Ashbrook (1988) assumes that mood draws on working memory resources, since working memory resources are finite. This would imply that mood diminishes the resources available for task purposes. Assumptions of the model have primarily been tested for negative mood (specifically, depressed and anxious mood), but have recently been corroborated for positive mood as well (cf. Meinhardt and Pekrun in press).

Alternative views: Positive effects of positive mood. The assumptions of these four approaches would imply that 'our primary goal is to feel good, and feeling good makes us lazy thinkers who are oblivious to potentially useful negative information and unresponsive to meaningful variations in information and situation' (Aspinwall 1998, p. 7). However, there are divergent views as well. Specifically, the work by Isen and colleagues has shown that positive mood can facilitate divergent thinking and creative, flexible thinking, thus serving efficient problem-solving in many situations, instead of compromising it (cf. Isen 1999). Furthermore, it has been shown that positive mood can facilitate performance at secondary tasks (Bless et al. 1996). Finally, recent experimental evidence shows that positive mood can generally enhance elaborate processing, even of negative information, when the subject has the goal of solving a problem, rather than the goal of just maintaining present positive mood (cf. Aspinwall 1998). This latter finding may be of specific importance in helping to deduce assumptions on self-regulation in real-life educational settings. A student's life is typically characterized by the pursuit of many goals, instead of just being oriented toward maintaining momentary good mood.

Limitations of experimental mood research. Generally, it seems that traditional mood research has suffered from a number of limitations which reduce the generalizability of results to real-life field settings. Three limitations may be of specific importance. First, with few recent exceptions (e.g. Levine and Burgess 1997), experimental mood research has focused on generalized positive versus negative mood states, at the expense of analysing more specific moods and emotions which may be more characteristic of human everyday life. Also, in many experimental procedures traditionally used, the specific profile of mood states which was triggered by mood induction procedures remained somewhat unclear, thus making interpretations of results ambiguous. Specifically, both positive and negative mood may comprise mood states implying different degrees of activation (e.g. frightened versus sad negative mood, excited versus relaxed positive mood; cf. Watson et al. 1999). The 
degree of activation implied by mood, however, can make quite a difference in terms of cognitive and behavioural effects. Second, due to methodological and ethical constraints, the mood effects of experimental induction procedures are relatively mild, thus undermining generalizability with respect to more intense emotional states.

Finally, many results of experimental mood research have been weak, lacked robustness, and remained inconsistent, which may in part be due to the two first-mentioned limitations. In some relevant traditions of research, even if findings consistently proved to be replicable within one specific laboratory, they proved not to be replicable in others (a case in point is research on affective priming; cf. Klauer 1998).

The usefulness of experimental mood research for explaining students' agency and performance thus seems to be limited. The results of this research are in danger of lacking ecological validity. Because of its inherent limitations, many studies of experimental mood research can be regarded as primarily being of an exploratory nature. They can provide valuable hypotheses, but cannot substitute the more direct analysis of real-life effects of affective states on students' learning, achievement, and self-regulation.

\section{Lack of research linking positive emotions to learning and achievement}

Whereas effects of positive mood have been studied extensively, the impact of discrete positive emotions on learning and performance has been analysed much less often (see Pekrun and Frese 1992). However, there are some exceptions as well. Specifically, there are a number of studies which have investigated relations of task-related enjoyment to various kinds of performance (e.g. Ferris and Gerber 1996; Helmke 1993; Larson et al. 1985; Puca and Schmalt 1999). In contrast to assumptions of experimental mood research, these studies consistently found that enjoyment had a positive influence on performance. For example, Larson et al. (1985) reported that high school students' enjoyment experienced while pursuing scholastic projects correlated significantly with the grade they received upon finishing the project $(r=0.44)$. In the study by Helmke (1993), elementary school children's enjoyment of learning at school correlated positively with academic effort, attention, grades, and achievement at scholastic tests. In longitudinal causal analysis, it turned out that these correlations were produced both by effects of enjoyment on achievement, and by reverse effects of achievement on enjoyment (however, the latter effects proved to be somewhat stronger than emotion effects on achievement).

The evidence of these studies suggests that positive emotions and students' performance are related in positive ways. However, since the number and range of studies are limited, no firm conclusions can be drawn to date. Before generalizations can be made, more research is needed which should investigate the relationship of different positive emotions to various facets of learning and performance in student populations ranging in age, ethnicity, and cultural background.

\section{Assumptions of a cognitive-motivational model}

In line with some of the approaches of mood research, we formulated a cognitivemotivational model which assumes that the effects of discrete emotions on learning and achievement are mediated both by cognitive processes and by motivational mechanisms (Pekrun 1992b; Pekrun et al. in press). Specifically, it is assumed that motivation and effort, strategies of learning and problem-solving, cognitive resources, and self-regulatory 
processes are primary mechanisms mediating the impact of emotions on learning and achievement.

Concerning the impact of mood and emotions on mediating processes and resulting achievement, it is important to distinguish between positive and negative affective states, as has been done by traditional mood research. However, it should prove fruitful to add a second traditional dimension differentiating affective states, namely, activation (cf. Watson et al. 1999). These two dimensions can be regarded as largely orthogonal, implying that four basic categories of emotions can be distinguished: positive activating and deactivating emotions, and negative activating and deactivating emotions. Examples of positive activating emotions are enjoyment, excitement, hope, and pride, and of positive deactivating emotions relief, relaxation, and contentment.

Furthermore, a third distinction should be important from an educational perspective as well. This distinction implies that there is a differentiation between emotions relating to inherent properties of task activities, and emotions relating to the outcomes of these activities. Borrowing terms from motivation research, activity-related emotions can be considered as intrinsic emotions, and outcome-related emotions as extrinsic emotions (Pekrun 1998). Intrinsic emotions like enjoyment of learning are based on interest in the process of learning, or in the objects of learning, whereas extrinsic emotions pertain to outcomes like success, failure, career consequences, etc.

The model assumes that positive emotions of these different categories influence mediating processes and resulting achievement in the following ways.

Motivation. Students' goal pursuit in academic settings is probably less characterized by goals of momentary mood maintenance, and more by goals of attaining mastery and achievement, avoiding failure, obtaining positive social reactions, etc. This implies that academic approach and avoidance goals pursued at school and university should be more important for students' positive emotions than goals of mood maintenance or mood repair. More specifically, concerning activating positive emotions, it can be assumed that such emotions enhance the action readiness (Frijda 1986) to perform academic task activities, and to pursue outcome-related academic goals. For example, both intrinsic enjoyment of learning and extrinsic joy and pride relating to success should strengthen the motivation to continue learning. This process can be facilitated by mood congruency effects implying that positive emotions enhance attention to and retrieval of positive taskand self-related appraisals from memory, like positive self-efficacy expectations further strengthening motivation (cf. Olafson and Ferraro 2001).

The situation may be more complex for deactivating positive emotions, however. Emotions like relief and relaxation can reduce any momentary motivation for effortful task engagement. On the other hand, these emotions can serve as reinforcers after task completion, thus strengthening motivation to engage in the next phase of learning. This would imply that deactivating positive emotions can be detrimental from a short-term perspective, but beneficial in the long run.

Learning strategies. Since activating positive emotions can strengthen motivation and the effortful pursuit of academic goals, they can also be assumed to benefit the elaborate processing of relevant information, including metacognitive and cognitive strategies of learning. In addition, generalizing from the evidence on mood and problem-solving, it can be assumed that creative, flexible, and holistic strategies are fostered by activating positive emotions. 
Furthermore, since emotions serve functions of directing attention towards the object of emotion, intrinsic activating emotions like enjoyment of learning can focus attention on the learning task at hand. Task enjoyment should thus be a primary source of activity-related flow experiences (Csikszentmihalyi and Csikszentmihalyi 1988).

In contrast, the effects of deactivating positive emotions can again be equivocal and less easy to predict. These emotions can also be assumed to create a broadened mindset facilitating creative ways of thinking. On the other hand, they may be counterproductive for any more elaborate processing of information, producing more shallow, superficial information processing instead, in similar ways as has generally been assumed for positive mood by experimental mood research (as outlined above). However, there is a caveat here as well. Creative, divergent thinking may sometimes require one to loosen one's mind to such an extent that there is no longer any conscious pursuit of task goals at all. This would imply that phases of creative thinking needing elaborate, complex recombination of information may well be fostered by temporary emotional deactivation as implied by relaxation and contentment, even if this recombination of information does only in part take place at the level of conscious elaborate processing.

Cognitive resources. Mood research has shown that positive mood can reduce attention and working memory resources. It would be misleading, however, to simply generalize this finding to positive emotions in academic settings. Specifically, intrinsic task enjoyment serves functions of directing attention toward the task, thus allowing one to make full use of cognitive resources instead of reducing them. Extrinsic positive emotions, on the other hand, can indeed distract attention away from the task. For example, pride can focus attention on the self, and admiration on another person, thus reducing working memory resources available for task purposes.

Self-regulation of learning. Setting goals, planning, monitoring, and evaluating learning requires flexible information processing which adapts behaviour to goals and task demands. As argued above, this type of information processing should be fostered by positive emotions, although more so by activating than by deactivating positive emotions. By implication, emotions like enjoyment, hope, and pride should foster students' selfregulation of learning.

Academic achievement. The above assumptions imply that intrinsic activating positive emotions enhance motivation, facilitate elaborate information processing, benefit creative and flexible ways of thinking, direct attention towards task performance, and help selfregulation, implying that they should be beneficial for resulting academic achievement.

Extrinsic and deactivating positive emotions, on the other hand, can exert positive as well as negative effects on different mediating processes, implying that their achievement effects should be more complex. In these emotions, achievement effects can depend on specific interactions between mediating processes and task demands which determine the relative importance of mechanisms benefitted or undermined by the respective emotion. Nevertheless, concerning extrinsic activating emotions like hope and pride, positive motivational and processing effects should be stronger in most cases than any distraction of attention induced by them, implying overall beneficial effects as well. The effects of deactivating positive emotions, however, may remain more equivocal since these emotions can reduce immediate motivation and distract attention, but can also strengthen long-term motivation to pursue academic goals. 
In sum, a realistic theoretical account of positive emotions' effects on academic learning and achievement implies that beneficial effects of positive emotions may far outweigh their potential costs under most conditions. One more general implication of such a theoretical analysis is that it would be misleading to assume that findings from experimental laboratory research could be generalized to real-life academic field settings in any simple ways, without taking the specific goal structures of these settings into account.

\section{Empirical findings}

We tested parts of the above assumptions in a series of seven cross-sectional, three longitudinal, and one diary-based study. The samples of these studies consisted of university and school students (cf. Pekrun et al. 1996, in press; Pekrun and Hofmann 1999; Titz 2001). In these studies, we used trait or state versions of the AEQ scales to measure students' emotions. German versions of the Study Interest Scale (Winteler et al. 1991) were used for assessing students' academic interest, trait and state versions of a German adaptation of the Motivated Strategies for Learning Questionnaire (MSLQ) to measure learning strategies and effort (Winteler et al. 1991; based on Pintrich et al. 1993), scales assessing task-irrelevant thinking when learning and taking tests as (negative) indicators of the availability of cognitive resources (adapted from Sarason 1984), and grades as well as performance at written exams as indicators of academic achievement (Perry et al. 2001).

The results showed that students' positive emotions do in fact relate in signficant ways to their learning and achievement. This was true of trait positive emotions as well as of course-related and state positive emotions. By and large, relations proved to be equivalent for university and secondary school students, and for German and Canadian students. Specifically, the following findings on mediating mechanisms and academic achievement emerged.

Motivation and effort. As expected, the activating positive emotions of enjoyment, hope, and pride correlated positively with students' interest, intrinsic academic motivation (i.e. motivation to learn because the material is interesting and learning is enjoyable), extrinsic academic motivation (motivation to learn in order to attain outcomes), total motivation to learn, and self-reported academic effort. These relations were somewhat stronger for learningrelated and class-related emotions than for test emotions. Correlations with interest and intrinsic motivation were higher for enjoyment, whereas relations with extrinsic motivation were higher for the extrinsic emotion of pride. For example, correlations of learning-related enjoyment, hope, and pride with intrinsic academic motivation were $r=0.61,0.41$, and $0.30(p<0.001)$ in a study with $N=230$ university students (Titz 2001), whereas correlations with extrinsic academic motivation were $r=0.20(p<0.01), 0.30$, and $0.43(p<0.001)$. Correlations with resulting effort were $r=0.43,0.49$, and 0.34 $(p<0.001)$, thus pointing to the importance of both enjoyment and hope.

Concerning deactivating positive emotion, there is one relevant scale in the AEQ, namely, the test relief scale. As expected theoretically, correlations between relief and motivational variables were much less strong, most of them being non-significant and close to zero (cf. Molfenter 1999). This is in line with expectations relating to equivocal motivational effects of deactivating positive emotions. On the other hand, relations between relief and motivation could in part be epiphenomena of relations between 
anxiety and motivation, since relief is a tension-reducing emotion which can be tied to preceding negative affective states (as noted above, test relief and anxiety correlated positively in our studies; Molfenter 1999).

Learning strategies. Enjoyment, hope, and pride related positively to students' metacognitive strategies at learning, and to the flexible cognitive strategies of elaboration, organization, and critical thinking (e.g. $r=0.44, p<0.001$, between enjoyment of learning and elaboration in Titz 2001). This suggests that activating positive emotions can in fact facilitate flexible, creative modes of thinking and learning. However, an alternative interpretation would be that creative learning is more enjoyable. Concerning more rigid ways of learning, correlations of activating positive emotions with rehearsal strategies were also positive, but most of them were near zero and not significant. Finally, the correlations between relief and rehearsal were near zero as well. This pattern of relations implies that there is a strong, specific relationship between activating positive emotions and flexible strategies of learning, which is consistent with our theoretical expectations.

Cognitive resources. As expected, the relations between enjoyment and irrelevant thinking during learning and test taking were consistently negative (e.g. $r=-0.38, p<0.01$, for learning-related enjoyment and irrelevant thinking during learning in Titz, 2001), which is in line with the assumption that intrinsic positive emotions can focus attention on the task. However, somewhat contrary to our expectations, relations for hope and pride proved to be negative as well. One possible interpretation is that positive motivational effects of these emotions on attention are stronger than any attention-diverting effects of implied cognitions about the self and the future. Relief, finally, did not relate significantly to task-irrelevant thinking.

Self-regulation versus external regulation of learning. Motivation, learning strategies, and attention can be regarded as key components of students' self-regulated learning. To regulate one's learning, however, involves more than being motivated, using learning strategies, and deploying cognitive resources. We used two newly developed scales to measure students' perceptions of self-regulation versus external regulation of their learning (Titz 2001). These two scales pertain to self-regulation versus external regulation by others concerning the goals of learning, the material used, the strategies of learning employed, and the monitoring and evaluation of outcomes. The two scales are moderately positively correlated, implying that self-regulation and external regulation need not be contradictory.

Enjoyment, hope, and pride correlated positively with self-regulation, which conforms to our assumptions (e.g. $r=0.43,0.46$, and $0.37, p<0.001$, in Titz 2001). These emotions were essentially unrelated to external regulation. Relief related positively to both types of regulation, but correlations were low (Molfenter 1999). Again, the pattern of relations suggests that there is a special relationship between activating positive emotions, on the one hand, and flexible ways of handling one's learning, on the other.

Academic achievement. Activating positive emotions related positively to students' academic achievement, whereas relief was essentially unrelated (cf. Pekrun et al. 1996; Pekrun and Hofmann 1999; Titz 2001). Typical correlations between learning-related, class-related, and test-related enjoyment, hope, and pride, on the one hand, and university grades, on the other, were in the range of $0.30<r<0.50$ (Molfenter 1999; Titz 2001). Correlations between secondary school students' positive emotions and their scholastic 
grades were of the same magnitude (Goetz 2002). These coefficients imply that positive emotions explain up to 25 per cent of the variance in achievement scores, a percentage of variance which is notably larger than the 10 per cent of variance typically explained by the well-researched emotion of test anxiety (Hembree 1988). Finally, from a longitudinal perspective, university students' enjoyment, hope, and pride measured early in the semester predicted grades as well as final course exam scores at the end of the semester (e.g. Pekrun et al. 2000).

Taken together, these findings imply that students' activating positive emotions relate in positive ways to academic motivation, effort spent at academic tasks, use of flexible strategies, availability of attentional resources, self-regulation of learning, and academic achievement. They are essentially unrelated to rehearsal strategies and to external regulation of learning, implying that they neither foster nor undermine more rigid approaches to learning. The deactivating emotion of relief proved to be unrelated to all of these variables of learning and achievement. However, it would be premature to generalize from relief to other deactivating positive emotions, since emotions like relaxation and contentment can relate to learning and achievement in a different way.

In sum, it turns out that enjoyment, hope, and pride relate to students' academic goal pursuit and outcomes in much more positive ways than might have been inferred from some of the findings of experimental mood research. However, the limitations of this evidence should be noted as well. Specifically, even predictive, longitudinal evidence does not imply that emotion effects on learning and performance are the only relevant direction of causation. Rather, it may be assumed that positive emotions, learning, and achievement are linked by reciprocal causation, positive emotions fostering achievement, but feedback of positive achievement in turn enhancing positive emotions. It is this kind of positive feedback loop which has been found by Helmke's study of learning-related enjoyment in school students cited above (Helmke 1993).

In addition, on a more general level, it can be quite misleading to infer from the sample statistics normally derived from correlational and experimental studies that the implied relations between variables do in fact apply to all subjects under study. Rather, correlational studies of the kind addressed here imply an analysis of relationships between individual differences in two or more variables. To ensure generalizability to intraindividual psychological functioning requires the more direct analysis of within-person functional relations (cf. Schmitz and Skinner 1993).

This is what we did in an idiographic-nomothetic diary study analysing the development of daily exam-related emotions of $N=72$ students over a period of six weeks before and during final university exams. In this study, we calculated intraindividual correlations between daily emotions and variables of exam-related learning for each individual student, and analysed if these correlations were generalizable across the students of the sample. One main result was that, by and large, relations of positive emotions to learning proved to be similar for different students and equivalent to the respective interindividual correlations, thus indicating functional homogeneity of positive emotions across students. For negative emotions, a more complicated picture emerged (Pekrun and Hofmann 1999; cf. Pekrun et al. in press). Concerning positive emotions, the evidence of this study strengthens the conclusions reached on the basis of interindividual relations as outlined above. 


\section{Cognitive and social origins of students' positive emotions: implications of control-value theory}

The assumptions and findings presented in the last section imply that positive emotions in education can make a big difference. Consequently, it would pay to attend to their antecedents, and to make an attempt to enhance them by educational intervention and in ordinary classroom instruction. To date, the sources of students' positive emotions are largely unexplored, in contrast to the antecedents of negative emotions like test anxiety (Hembree 1988; Zeidner 1998). Attributional research on the role of causal attributions in positive achievement emotions is the only major exception (Weiner 1985). The studies which are available seem to converge concerning the importance of two classes of individual antecedents inducing positive emotions, namely, (a) students' academic expectations, causal attributions, and self-evaluations of abilities, and (b) their interest in academic tasks and task-related goals (e.g. Ferris and Gerber 1996; Helmke 1993; Larson et al. 1985).

Academic expectations, causal attributions, and self-concepts relate to students' perceived control over academic actions and outcomes, and interest and goals to the values they attach to these actions and outcomes. In a recent control-value theory of achievement emotions, we made an attempt to integrate theoretical formulations addressing these two classes of antecedents (cf. Pekrun 1998, 2000; Pekrun et al. in press). Implications of this theory for antecedents of students' positive emotions, reciprocal linkages of emotions and antecedents, and educational applications will be discussed in turn.

\section{Individual antecedents of students' positive emotions}

Beyond genetic dispositions and physiological processes, cognitive appraisals can be regarded as main sources of human emotions. Control-value theory of achievement emotions posits that control-related and value-related appraisals are main determinants of achievementrelated emotions. Examples of control-related cognitions are retrospective causal attributions, prospective causal expectancies (e.g. self-efficacy and action-outcome expectations), and state-related control cognitions relating to the present situation. Important valuerelated types of appraisals are intrinsic values and goals relating to inherent properties of activities, and extrinsic values and goals pertaining to their outcomes. In taking these different types of control and value cogitions into account, the theory attempts to integrate assumptions of expectancy-value and attributional theories of achievement-related emotions (Weiner 1985; Pekrun 1992c).

Consistent with basic assumptions of expectancy-value models of affect and motivation, the theory postulates that subjective control and values interact in such ways that both of them are necessary for academic emotions to arise. For example, it is assumed that enjoyment of learning presupposes that the student expects to be able to master the material, and is sufficiently interested in learning this material. Pride about success in a specific domain is assumed to be induced when the student attributes success to internal causes making achievement controllable (the causes as such can be controllable or uncontrollable, as with controllable effort and uncontrollable dimensions of ability), and sufficiently values success in this domain. However, control and value cognitions need not be processed 
each time an emotion emerges. In habitualized emotions, situational perceptions and emotions can be short-circuited (Pekrun 1988). In any case, however, they are supposed to be crucial when the emotion is learned initially (one specific exception is automatic processes of emotional contagion in classroom interactions; cf. Hatfield et al. 1994).

In some of our field studies on academic emotions, variables of students' academic control and values were included. In these studies, it turned out that academic self-efficacy, academic control of achievement, subjective values of learning activities, and subjective values of academic success and failure correlated positively with students' enjoyment, hope, and pride (cf. Pekrun 1998, 2000; Molfenter 1999; Titz 2001). Also, academic control measured early in the semester predicted enjoyment of university courses and related intrinsic motivation throughout the semester, thus corroborating the affective importance of academic control in longitudinal ways (cf. Pekrun et al. 2000; Perry et al. 2001).

Moving beyond main effects, a recent study by Barrera (2001) considered whether interactions of academic control and values can explain university students' emotions pertaining to statistics courses, including the enjoyment of such courses. Statistics is a subject which causes academic worries and undermines motivation in many of our students today. The results of this study implied significant interactions. In line with assumptions of control-value theory, enjoyment was high when both academic control in the domain of statistics and the subjective importance of this domain were high, whereas enjoyment was low when either control or value or both were low. By implication, any intervention making an attempt to ameliorate our students' approach to statistics should profit from paying attention both to students' sense of mastery and control in this domain, and to the value and usefulness they attribute to this subject.

\section{Instructional and social antecedents of students' positive emotions}

In line with social cognitive theories of affect and personality, control-value theory assumes that the impact of social environments on emotions is mediated by subjective appraisals. This implies that the theory's assumptions about cognitive antecedents of emotions can also be used to deduce hypotheses on their environmental origins. Environmental factors of specific importance should be those variables which influence control and value appraisals initially, thus indirectly affecting students' emotions as well. This can be assumed for the following groups of variables (Fig. 8.1; Pekrun 1998, 2000).

1. The quality of classroom instruction can be assumed to exert direct effects both on students' mastery and perceived academic control (Perry 1991), and on subjective values of academic learning, thus also affecting their emotions. Probably, there are different mechanisms underlying these effects. Modeling effects of teachers' behaviour, including teachers' expressed emotions, and the impact of quality instruction on students' mastery of learning may be of specific importance.

2. Autonomy support can meet students' needs for self-regulation, thus creating positive experiences of learning which can induce positive values as well. In addition, autonomy support can benefit the development of mastery and, therefore, the emergence of subjective control. 
3. Social achievement expectancies and values conveyed by significant others, by educational goal structures, and by classroom interaction structures (like cooperation versus competition; see Chapter 10 in this volume) imply messages about aspiration levels and probabilities of success and failure, and about the importance of achievement, thus influencing students' achievement-related expectancies and values.

4. Feedback and consequences of achievement underly the formation of students' achievement expectancies, of outcome expectancies relating to parents' and teachers' social reactions, career opportunities etc., and of related perceptions of the instrumental value of achievement. Causal attributions can be of specific importance in mediating these effects (Weiner 1985).

5. Finally, support and social relatedness with parents, teachers, and peers in learning contexts can help students to deal with failures, thus strengthening positive expectancies, and to meet their needs for affiliation, which can foster the development of positive value perceptions pertaining to learning and achievement.

Consistent with these assumptions, findings of our field studies showed that teacher enthusiasm, positive feedback of achievement, as well as cooperation and affiliation within the classroom correlated positively with students' enjoyment of learning and hope for success. This evidence included both cross-sectional correlations and longitudinal prediction (cf. Pekrun 1998, 2000; Pekrun et al. 2000).

\section{Reciprocal linkages between social environments and students' positive emotions}

Control-value theory and the assumptions of our cognitive-motivational model on emotion effects imply that social environments influence students' positive emotions, and that emotions in turn affect academic learning and achievement. Taken individually, the assumptions of the two models would imply unidirectional causation. Taken together,

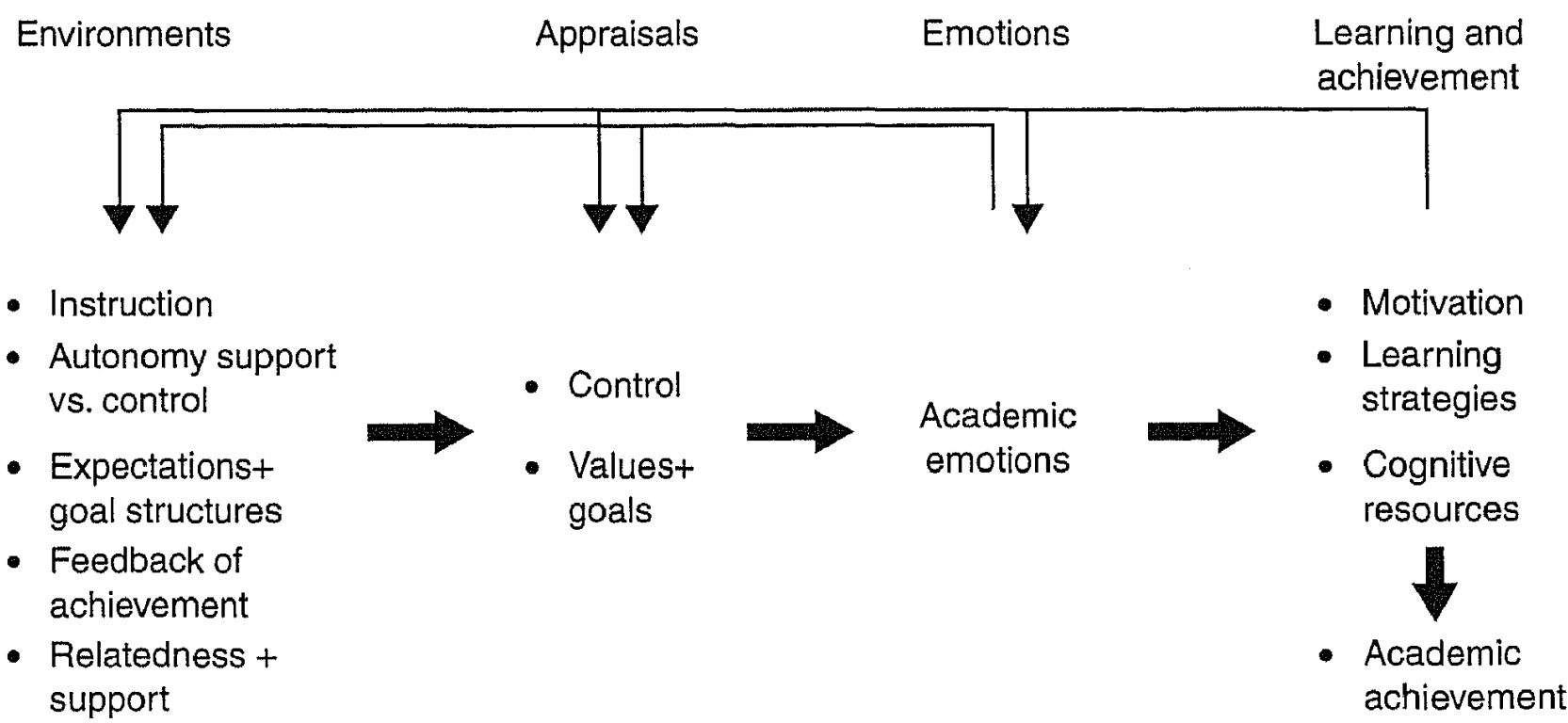

Figure 8.1 Control-value theory of emotions: linkages between emotions, effects, and antecedents. 
however, they suggest that antecedents, emotions, and effects can be linked by reciprocal causation (Fig. 8.1).

For example, as outlined in the last section, positive emotions can foster students' achievement, but positive feedback of achievement is a major source of positive academic emotions (Weiner 1985), thus implying positive feedback loops between emotions and achievement. In a similar vein, the behaviour of significant others can influence students' academic control, values, and emotions, but students' can in turn affect the behaviour of educators. A case in point is teachers' enthusiasm which may be important for students' academic experiences, but can strongly be influenced by students' positive classroom emotions. Evidence on reciprocal linkages of this kind is largely lacking to date. One notable exception is the study by Helmke (1993). As cited above, this study found that elementary school students' enjoyment of learning positively influenced their academic achievement across the schoolyears, but was dependent on prior positive feedback of achievement, thus implying positive feedback loops between emotions, achievement, and feedback of achievement.

\section{Implications for intervention and classroom instruction}

Control-value theory can serve as a theoretical basis for designing measures of intervention and classroom instruction fostering students' positive emotions. Such measures can focus on students' appraisals underlying their emotions, or on instruction and social environments influencing appraisals and emotions. Concerning appraisals, the theory implies that methods influencing control and values should be of specific importance. An example is reattributional training which can help students to develop a feeling of control over important subjective outcomes by reshaping their causal attributions of success and failure. Reattributional training procedures can be used with individual students, but can be integrated into ordinary classroom instruction as well (cf. Foersterling 1985; Perry and Penner 1990; Perry et al. 1993).

As to the design of educational environments, the above assumptions on environmental influences suggest a number of ways to foster students' emotions (cf. also Astleitner 2000; Covington 1992). Improving the quality of instruction and being enthusiastically engaged in teaching can be a primary way of doing so. A second important method would be to give students autonomy to regulate their learning. However, a precondition would be sufficient competences for self-regulation by the students, implying that support by the teacher may be needed for younger students, and for students with regulatory problems (e.g. volitional problems like procrastination). Third, teachers and parents can foster students' affect by conveying achievement expectancies and values which challenge students without pushing demands beyond their capabilities. Fourth, concerning feedback of achievement, opportunities for success inducing positive emotions can be increased by using individual and criterion-oriented reference norms for giving feedback, instead of - or in addition to social grading which seems to dominate scholastic feedback systems. Also, creating academic cultures of learning from errors and perceiving them as chances to improve, instead of being punished for them, can reduce negative emotions and thus lay the groundwork for positive affective experiences even in cases of non-mastery. Finally, creating reliable social bonds with students can help in conveying positive academic values and maintaining a 
mastery-oriented climate preventing the development of anti-achievement norms prevailing in many classrooms today.

\section{Conclusions}

As of yet, psychology as well as educational research have neglected the positive side of human affective life. One underlying implicit assumption seems to be that positive emotions should be less important for theoretical explanations of human agency and related practical applications than their negative counterparts (cf. also Fredrickson 2001). In this chapter, we argued that positive emotions are no less important than negative affect. We outlined theoretical assumptions and empirical findings of our programme of research into students' academic emotions, and in doing so, we focused on occurrence, measurement, effects, and antecedents of students' positive emotions.

Findings implied that students experience a great variety of positive task-related, selfreferenced, and social emotions in academic settings when attending classes, studying, and taking tests and exams. Judging from the results of our exploratory studies, positive academic emotions are experienced no less often by students than negative emotions like test anxiety. In contrast to assumptions which might be deduced from experimental mood research, many of these positive emotions prove to be beneficial for students' learning and pursuit of challenging academic goals. Specifically, this is true for activating positive emotions like enjoyment of learning, hope for success, and academic pride. The control-value theory outlined here implies that perceived academic control and subjective values of academic mastery and achievement can be primary individual sources of these positive emotions, and classroom instruction as well as social environments important external sources. One implication is that there can be many ways of fostering students' positive emotions by addressing individual appraisals or instructional and social antecedents inducing such emotions.

However, there are also some limitations to the studies on students' positive emotions which have been conducted thus far, including our own studies. For example, even predictive evidence produced by longitudinal studies does not yet give an account of reciprocal linkages between positive emotions, effects, and antecedents, and of the relative importance of different causal directions. Even more importantly, intervention research testing assumptions on ways to foster students' positive emotions is still largely lacking.

Such limitations notwithstanding, the evidence presented in this chapter suggests that a realistic account of students' agency and goal pursuit requires us to take their positive emotions into account. Educational research should move beyond the analysis of test anxiety which has dominated in the past, and study the full range of students' academic emotions, paying no less attention to their positive affective experiences than to their negative emotions.

\section{Acknowledgements}

This research was supported by three research grants to the first author from the German Research Foundation (Pe 320/7-2, 320/7-3,320/11-1) and by a grant to the first and fourth authors from the German American Academic Council. 


\section{References}

Aspinwall, L. (1998). Rethinking the role of positive affect in self-regulation. Motivation and Emotion, $22,1-32$.

Astleitner, H. (2000). Designing emotionally sound instruction. Instructional Science, 28, 169-98.

Atkinson, J. W. (1964). An introduction to motivation. Princeton, NJ: van Nostrand.

Barrera, A. (2001). Students' conceptions of intelligence, emotions, and achievement in university statistics courses. Unpublished master's thesis, University of Munich, Germany.

Bless, H., Clore, G. L., Schwarz, N., Golisano, V., Rabe, C., and Wölk, M. (1996). Mood and the use of scripts: Does a happy mood really lead to mindlessness? Journal of Personality and Social Psychology, 71, 665-79.

Bower, G. H. (1981). Mood and memory. American Psychologist, 36, 129-48.

Clore, G. L., Schwarz, N., and Conway, M. (1994). Affective causes and consequences of social information processing, in R. S. Wyer and K. Skrull (eds.), Handbook of social cognition, 2nd edn, pp. 323-417. Hillsdale, NJ: Erlbaum.

Covington, M. V. (1992). Making the grade: A self-worth perspective on motivation and school reform. New York: Cambridge University Press.

Curry, L. A., Snyder, C. R., Cook, D. L., Ruby, B. C., and Rehm, M. (1997). Role of hope in academic and sport achievement. Journal of Personality and Social Psychology, 73, 1257-67.

Csikszentmihalyi, M. and Csikszentmihalyi, I. S. (eds.). (1988). Optimal experience: Psychological studies of flow in consciousness. New York: Cambridge University Press.

Ellis, H. C. and Ashbrook, P. W. (1988). Resource allocation model of the effect of depressed mood states on memory, in K. Fiedler and J. Forgas (eds.), Affect, cognition, and social behaviour. Toronto: Hogrefe International.

Ferris, J. and Gerber, R. (1996). Mature-age students' feelings of enjoying learning in a further education context. European Journal of Psychology of Education, 11, 79-96.

Foersterling, F. (1985). Attributional retraining: A review. Psychological Bulletin, 98, 495-512.

Forgas, J. P. (1995). Mood and judgment: The Affect Infusion Model (AIM). Psychological Bulletin, $117,39-66$.

Fredrickson, B. L. (2001). The role of positive emotions in positive psychology: The broadenand-build theory of positive emotions. American Psychologist, 56, 218-26.

Frijda, N. (1986). The emotions. Cambridge: Cambridge University Press.

Frydenberg, E. (1997). Adolescent coping: Theoretical and research perspectives. London: Routledge.

Goetz, T. (2002). Students' emotions in mathematics. Unpublished dissertation. University of Munich: Department of Psychology.

- Pekrun, R., Perry, R. P., and Hladkyi, S. (2001). Academic emotions questionnaire: Codebook for English-language scale versions (Technical report). University of Munich: Department of Psychology.

Gottfried, A. E., Fleming, J. S., and Gottfried, A. W. (2001). Continuity of academic intrinsic motivation from childhood through late adolescence: A longitudinal study. Journal of Educational Psychology, 93, 3-13.

Hatfield, E., Cacioppo, J. T., and Rapson, R. L. (1994). Emotional contagion. New York: Cambridge University Press.

Heckhausen, H. (1980). Motivation und Handeln (Motivation and action). Berlin: Springer. 
Helmke, A. (1993). Die Entwicklung der Lernfreude vom Kindergarten bis zur 5. Klassenstufe (Development of affective attitudes towards learning from kindergarten to grade five). Zeitschrift fuer Paedagogische Psychologie, 7, 77-86.

Hembree, R. (1988). Correlates, causes, effects, and treatment of test anxiety. Review of Educational Research, 58, 47-77.

Hodapp, V. and Benson, J. (1997). The multidimensionality of test anxiety: a test of different models. Anxiety, Stress and Coping, 10, 219-44.

Holzwarth, A. (1997). Emotionen in schulischen Prüfungssituationen: Eine explorative Interviewstudie (Emotions in exams at school: An exploratory interview study). Unpublished master's thesis. University of Regensburg: Institute of Psychology.

Isen, A. M. (1999). Positive affect, in T. Dalgleish and M. J. Powers (eds.), Handbook of cognition and emotion, pp. 521-39. New York: Wiley.

Klauer, C. (1998). Affective priming. European Review of Social Psychology, 8, 63-107.

Larson, R., Hecker, B., and Norem, J. (1985). Students' experience with research projects: Pains, enjoyment and success. High School Journal, 69, 61-9.

Levine, L. J. and Burgess, S. L. (1997). Beyond general arousal: Effect of specific emotions on memory. Social Cognition, 15, 157-81.

Meinhardt, J. and Pekrun, R. Attentional resource allocation to emotional events: An ERP study. Cognition and Emotion (in press).

Molfenter, S. (1999). Prüfungsemotionen bei Studierenden. Explorative Analysen und Entwicklung eines diagnostischen Instrumentariums (Test emotions in university students: Exploratory analysis and development of a diagnostic instrument). Unpublished dissertation. University of Regensburg: Institute of Psychology.

Olafson, K. M. and Ferrraro, F. R. (2001). Effects of emotional state on lexical decision performance. Brain and Cognition, 45, 15-20.

Pekrun, R. (1988). Emotion, Motivation und Persönlichkeit (Emotion, motivation and personality). München: Psychologie Verlags Union.

- (1992a). Kognition und Emotion in studienbezogenen Lern- und Leistungssituationen: Explorative Analysen (Cognition and emotion in academic situations of learning and achievement: exploratory analyses). Unterrichtswissenschaft, 20, 308-24.

- (1992b). The impact of emotions on learning and achievement: Towards a theory of cognitive/motivational mediators. Applied Psychology, 41, 359-76.

- (1992c). Expectancy-value theory of anxiety: Overview and implications, in D. G. Forgays, T. Sosnowski, and K. Wrzesniewski (eds.), Anxiety: Recent developments in self-appraisal, psychophysiological and health research, pp. 23-41. Washington, DC: Hemisphere.

- (1998). Schüleremotionen und ihre Förderung: Ein blinder Fleck der Unterrichtsforschung (Students' emotions: A neglected topic of educational research). Psychologie in Erziehung und Unterricht, 44, 230-48.

- (2000). A social cognitive, control-value theory of achievement emotions, in J. Heckhausen (ed.), Motivational psychology of human development, pp. 143-63. UK, Oxford: Elsevier.

- and Fend, H. (eds.) (1991). Schule und Persönlichkeitsentwicklung: Ein Resümee der Längsschnittforschung (Schools and personality development: Longitudinal studies). Stuttgart: Enke.

and Frese, M. (1992). Emotions in work and achievement, in C. L. Cooper and I. T. Robertson (eds.), International review of industrial and organizational psychology, Vol. 7, pp. 153-200. UK, Chichester: Wiley. 
Pekrun, R. Goetz, T., Titz, W., and Perry, R. P. Academic emotions in students' self-regulated learning and achievement: A programme of quantitative and qualitative research. Educational Psychologist (in press).

- Hochstadt, M., and Kramer, K. (1996). Prüfungsemotionen, Lernen und Leistung (test emotions, learning, and achievement), in C. Spiel, U. Kastner-Koller and P. Deimann (eds.), Motivation und Lernen aus der Perspektive lebenslanger Entwicklung, pp. 151-62. Münster: Waxmann.

- and Hofmann, H. (1999). Lern- und Leistungsemotionen: Erste Befunde eines Forschungsprogramms (Emotions in learning and achievement: First results of a program of research), in R. Pekrun and M. Jerusalem (eds.), Emotion, Motivation und Leistung, pp. 247-67. Göttingen: Hogrefe.

Molfenter, S., Titz, W., and Perry, R. P. (2000). Emotion, learning, and achievement in university students: Longitudinal studies. Paper presented at the annual meeting of the American Educational Research Association, New Orleans, LA.

Perry, R. P. (1991). Perceived control in college students: Implications for instruction in higher education, in J. Smart (ed.), Higher education: Handbook of theory and research, Vol. 7, pp. 1-56. New York: Agathon.

Hechter, F. I., Menec, V. H., and Weinberg, L. (1993). Enhancing achievement motivation and performance in college students: An attributional retraining perspective. Research in Higher Education, 34, 687-720.

Hladkyi, S., Pekrun, R., and Pelletier, S. T. (2001). Academic control and action control in the achievement of college students: A longitudinal field study. Journal of Educational Psychology, 93, 776-89.

- and Penner, K. S. (1990). Enhancing academic achievement in college students through attributional retraining and instruction. Journal of Educational Psychology, 82, 262-71.

Pintrich, P. R., Smith, D. A. F., Garcia, T., and McKeachie, W. (1993). Reliability and predictive validity of the Motivated Strategies for Learning Questionnaire (MSLQ). Educational and Psychological Measurement, 53, 801-13.

Puca, R. M. and Schmalt, H.-D. (1999). Task enjoyment: A mediator between achievement motives and performance. Motivation and Emotion, 23, 15-29.

Rapp, A. (1997). Emotionen in schulischen Unterrichts- und Lernsituationen: Eine explorative Interviewstudie (School students' emotions in classroom instruction and studying: An exploratory interview study). Unpublished master's thesis. University of Regensburg: Institute of Psychology.

Sarason, I. G. (1984). Stress, anxiety, and cognitive interference: Reactions to tests. Journal of Personality and Social Psychology, 44, 929-38.

Schaller, M. and Cialdini, R. B. (1990). Happiness, sadness, and helping: A motivational integration, in R. Sorrentino and E.T. Higgins (eds.), Handbook of motivation and cognition: Foundations of social behaviour, Vol. 2, pp. 265-96. New York: Guilford Press.

Scherer, K. R. (1984). On the nature and function of emotion: A component process approach, in K. R. Scherer and P. Ekman (Hrsg.), Approaches to emotion, pp. 293-317. Hillsdale, NJ: Erlbaum.

Schmitz, B. and Skinner, E. (1993). Perceived control, effort, and academic performance: Interindividual, intraindividual, and multivariate time series analyses. Joumal of Personality and Social Psychology, 64, 1010-28.

Schwarz, N. and Bohner, G. (1996). Feelings and their motivational implications: Moods and the action sequence, in P. M. Gollwitzer and J. A. Bargh (eds.), The psychology of action: Linking cognition and motivation to behavior, pp. 119-45. New York: Guilford Press. 
and Clore, G. L. (1996). Feelings and phenomenal experiences, in E. T. Higgins and A. W. Kruglanski (eds.), Social psychology: Handbook of basic principles, pp. 433-65. New York: Guilford.

Spangler, G., Pekrun, R., Kramer, C., and Hofmann, H. Students' emotions, physiological reactions, and coping at exams. Anxiety, Stress and Coping (in press).

Titz, W. (2001). Emotionen von Studierenden in Lernsituationen (University students' emotions at learning). Münster: Waxmann.

Turner, J. and Schallert, D. (2001). Expectancy-value relationships of shame reactions and shame resiliency. Journal of Educational Psychology, 93, 320-9.

Watson, D., Wiese, D., Vaidya, J., and Tellegen, A. (1999). The two general activation systems of affect: Structural findings, evolutionary considerations, and psychobiological evidence. Journal of Personality and Social Psychology, 76, 820-38.

Weiner, B. (1985). An attributional theory of achievement motivation and emotion. Psychological Review, 92, 548-73.

Winteler, A., Schiefele, U., Krapp, A., and Wild, K.-P. (1991). Skalen zu Studienintresse und Lernstrategien im Studium (Scales on study interest and learning strategies) (Technical report). Neubiberg/Munich, Germany: University of the German Army.

Zeidner, M. (1998). Test anxiety: The state of the art. New York: Plenum. 